Data de recebimento do artigo: 05-01-2018

Data de aceite do artigo: $17-06-2018$

DOI: https://doi.org/10.7769/gesec.v9i2.769

\title{
Sustentabilidade e intenção empreendedora: Estudo com discentes do curso de Administração da Universidade do Oeste de Santa Catarina (Unoesc)
}

\begin{abstract}
Amélia Silveira
Doutora em Ciências da Comunicação pela Universidade de São Paulo (ECA/USP). Pós-doutora em Ciencias de La Información pela Universidad Complutense de Madrid (Espanha) e Pós-doutora em Administração pela Universidade de São Paulo (FEA/USP). E-mail: ameliasilveira@ gmail.com
\end{abstract}

(Brasil)

\section{Sabrina do Nascimento}

Doutora em Administração e Turismo pela Universidade do Vale do Itajaí (Univali). Pós-doutoranda na Universidade de Desenvolvimento do Estado de Santa Catarina (Udesc).

E-mail: sabnascimento@gmail.com (Brasil)

\section{Larissa Riboldi}

Graduanda em Ciências Contábeis na Universidade do Oeste de Santa Catarina (Unoesc).

Bolsista do Projeto Uniedu. E-mail: laarissariboldii@gmail.com (Brasil)

\section{RESUMO}

O estudo aborda a orientação sustentável e o comportamento empreendedor voltados para a Intenção Empreendedora Social (IES) e a Intenção Empreendedora (IE) no contexto de uma instituição de ensino superior no Oeste de Santa Catarina, Brasil. Procurou-se responder à seguinte questão: Até que ponto os alunos apresentam visão social, intenção empreendedora social e intenção empreendedora? O delineamento metodológico foi descritivo. Aplicou-se um questionário estruturado para a coleta de dados utilizando escala de mensuração de sete pontos do tipo Likert. Responderam a esse questionário 70 alunos do Curso de Graduação em Administração da Universidade do Oeste de Santa Catarina (Unoesc) Chapecó, no ano 2017. A amostra foi intencional, de conveniência, não probabilística e por acessibilidade. Os resultados apresentaram que o empreendedorismo sustentável se encontra em desenvolvimento na literatura de administração. Constatou-se que os alunos apresentaram visão social, intenção empreendedora social e intenção empreendedora com concordância mediana.

Palavras-chave: Intenção empreendedora. Intenção empreendedora social. Visão social. Sustentabilidade. Comportamento empreendedor. 


\title{
Sustainability and entrepreneurial intention: Study with undergraduate administration students of Universidade do Oeste de Santa Catarina (Unoesc)
}

\begin{abstract}
This study is about the individual sustainable orientation and the entrepreneurial behavior focused on the Social Entrepreneurial Intention (SEI) and the Entrepreneurial Intention (EI) in the context of a higher education institution of the Western Santa Catarina, Brazil. It was sought to answer the following question: To what extent do the students present social view, social entrepreneurial intention, and entrepreneurial intention? The methodological design was descriptive. For the data collection, a structured questionnaire was applied using the 7-point Likert scale. 70 undergraduate Administration students of Universidade do Oeste de Santa Catarina (Unoesc), Chapecó, answered this questionnaire in 2017. The sample was intentional, convenience, no probabilistic and by accessibility. The results showed that the sustainable entrepreneurship is under development in administration literature. It was possible to confirm that the students have social view, social entrepreneurial intention, and entrepreneurial intention with medium agreement.
\end{abstract}

Keywords: Entrepreneurial intention. Social entrepreneurial intention. Social view. Sustainability. Entrepreneurial behavior.

\section{Como referenciar em APA:}

Silveira, A., Nascimento, S. \& Riboldi, L. (2018). Sustentabilidade e intenção empreendedora: estudo com discentes do curso de Administração da Universidade do Oeste de Santa Catarina (UNOESC). R.G.Secr.,GESEC, 9(2). DOI:

\section{Como referenciar em ABNT:}

SILVEIRA, A.; NASCIMENTO, S.; RIBOLDI, L. Sustentabilidade e intenção empreendedora: estudo com discentes do curso de Administração da Universidade do Oeste de Santa Catarina (UNOESC). R.G.Secr.,GESEC, v. 9, n. 2, 2018. DOI:
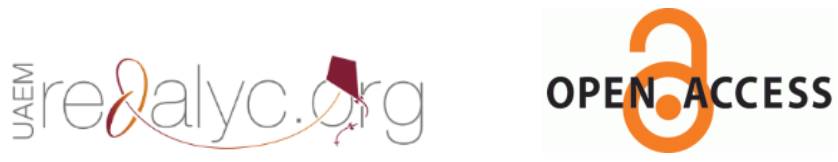


\section{Introdução}

O estudo do empreendedorismo sustentável vem crescendo significativamente na literatura internacional. Os anos de 2010 e 2011 são os mais produtivos, com autores e estudos considerados seminais para o tema, a exemplo de Cohen e Winn (2007) e Dean e McMullen (2007). Nos anos seguintes, as revisões de literatura de Hall, Daneke e Lenox (2010), Levinsohn (2012), Klewitz e Hansen (2014) e Schaefer, Corner e Kearins (2015) e Schaltegger, LudekeFreund e Hansen (2016) se destacam. Recentemente, o trabalho de Ploum (2018) merece citação. Da mesma forma, no Brasil, o assunto revela interesse crescente. Os estudos de Nassif, Prando e Cosetino (2010), Brunelli e Cohen (2012), Boszczowski e Teixeira (2012), Borges, Borges, Ferreira, Najberg e Tete (2013), Sehnem, Lucas e Marques (2015), e Silveira, Backes e Kobayashi (2017), entre outros, se destacam no tema.

Como campo de estudo pode-se afirmar que o empreendedorismo sustentável se evidencia na literatura de administração, ganhando importância no assunto. (Hall, Daneke, \& Lenox, 2010; Hockerts \& Wüstenhagen, 2010; Schaltegger \& Wagner, 2010; Pacheco, Dean, \& Payne, 2010; Shepherd \& Patzelt, 2011; Levinsohn, 2013; Klewitz \& Hansen, 2014; Schaefer, Corner, \& Kearins, 2015; Pinkse \& Groot, 2015; Jolink \& Niesten, 2015; Schaltegger, Ludeke-Freund, \& Hansen, 2016).

Neste estudo, a delimitação do tema apresenta, desde o início, a orientação sustentável individual e do comportamento empreendedor em organizações complexas e sociais. Mais especificamente, aspectos voltados para a Visão Social, a Intenção Empreendedora Social (IES) e a Intenção Empreendedora (IE). E, com aplicação no contexto de uma instituição de ensino superior no Oeste de Santa Catarina, Brasil. Para tanto, o estudo envolveu os alunos do Curso de Graduação em Administração da Universidade do Oeste de Santa Catarina (Unoesc), de Chapecó, no ano 2017. Os alunos de graduação, como sujeitos sociais pesquisados, são importantes como respondentes e também como indivíduos em formação, podendo ser considerados protagonistas de estratégias de ações empreendedoras sustentáveis individuais.

As pesquisas que se voltaram para a investigação da intenção de indivíduos para empreender, de forma sustentável, revelam suas características pessoais e socioeconômicas, atitudes e comportamentos quanto à visão social onde estão inseridos. Esses estudos se tornam importantes para aumentar o conhecimento sobre esse tema. Considerar aspectos específicos da sustentabilidade empreendedora quanto ao entendimento sobre o comportamento inicial do indivíduo que pretende ou tem a intenção de empreender revela-se como pouco estudado, até o 
momento. O artigo de Kuckertz e Wagner (2010) ampara este conteúdo, sendo base para o que aqui foi realizado, tendo considerado alunos e ex-alunos de universidade, em seu estudo.

Pesquisa com alunos de cursos de graduação em universidades, considerados sujeitos sociais em relação à coleta de dados primários, são consideradas importantes na literatura do tema. Contribuem para aumentar o conhecimento sobre o assunto de empreender e de empreender de forma sustentável, ao longo do tempo. Rueda, Moriano e Liñán (2015) salientam que inúmeras pesquisas foram realizadas considerando alunos de cursos de graduação em universidades, como respondentes. O estudo de Naia (2013), Couto, Mariano e Mayer (2010), Hecke (2011), Almeida (2013), Lovison (2014), Souza (2015), Souza e Silveira (2016), Souza, Silveira e Nascimento (2017), e Souza e Silveira (2018) podem ser citados.

Com base no que foi justificado, surge a questão que norteia a pesquisa: Até que ponto os alunos do Curso de Graduação em Administração da Unoesc, Chapecó, no ano de 2017, apresentam intenção de empreender com visão voltada para a sustentabilidade?

Para tanto, definiu-se como objetivo geral de pesquisa mensurar a intenção de adotar atitudes e comportamentos sociais, com comportamento empreendedor sustentável e ações voltadas para o empreendedorismo, em alunos do Curso de Graduação em Administração da Unoesc, Chapecó, em 2017.

Para tanto, foram os seguintes os objetivos específicos de compreensão e análise passaram a nortear a pesquisa:

a) caracterizar os alunos participantes da pesquisa quanto aos aspectos de gênero, idade, estado civil, renda própria e renda familiar;

b) identificar a visão social dos alunos pesquisados;

c) apontar a intenção empreendedora social;

d) distinguir a intenção empreendedora dos alunos respondentes.

Pode-se adiantar que se desconhecem, até o momento, estudos realizados no Brasil com essa perspectiva específica, na região oeste do estado de Santa Catarina.

A estrutura do presente artigo apresenta cinco partes, considerando como primeira a introdução. Em seguida, constam a revisão de literatura e o método de pesquisa. Na sequência a análise dos resultados e a conclusão, assim como as referências. 


\section{Revisão de literatura}

A revisão de literatura considera, desde o início, a intenção de adotar atitudes e comportamentos sociais, com comportamento empreendedor sustentável e ações voltadas para o empreendedorismo. Para tanto, faz-se necessário entender o que se considera como um empreendedor sustentável.

O empreendedor sustentável é o indivíduo que, por meio da descoberta, criação e exploração de oportunidades empresariais, e que contribuem para a sustentabilidade, gera ganhos econômicos, sociais e ambientais para a sociedade. É aquele que não se limita à solução de questões ambientais. (Hockerts \& Wüstenhagen, 2010; Pacheco, Dean, \& Payne, 2010; Shepherd \& Patzelt, 2011; Pinkse \& Groot, 2015; Jolink \& Niesten, 2015). Aprofundando o assunto, Jolink e Niesten (2015) deixam claro o entendimento da existência de duas categorias de agentes, que denominam de eco conscientes: 1) os empresários ecológicos - que buscam o mercado de massa com objetivos voltados aos lucros e ao meio ambiente, ao mesmo tempo, mas sem preocupação com questões sociais, sendo uma subcategoria de empreendedores sustentáveis; 2) os empreendedores sustentáveis - que objetivam integrar tanto o que precisa ser sustentado (natureza, ambiente, comunidades) quanto o que precisa ser desenvolvido (ganhos econômicos e não econômicos para os indivíduos e para a sociedade).

Aqui se inserem, como empreendedores sustentáveis os indivíduos que adotam atitudes e comportamentos sociais, juntamente com um comportamento empreendedor sustentável, e com a intenção de desenvolver ações voltadas para o empreendedorismo.

Por sua vez, o empreendedorismo sustentável é a forma pela qual os empreendedores sustentáveis obtêm rentabilidade financeira identificando lacunas, falhas ou imperfeições de mercado, de forma social e ambientalmente relevante. E, a partir dessa premissa, efetivam um empreendimento sustentável considerando os impactos de suas atividades na sociedade, procurando minimizar os efeitos ambientais e sociais negativos em sua cadeia produtiva. (Dean \& McMullen, 2007).

Wagner (2012) considera ainda o empreendedorismo sustentável como aquele estreitamente relacionado à inovação, sendo que seus níveis variam quando o assunto é relacionado à sustentabilidade. A inovação sustentável parece exigir inovações radicais, que melhoram maciçamente o desempenho ambiental ou social de bens ou processos de produção, sem alterar os benefícios do consumidor e utilidades. Por outro lado, considera as inovações incrementais - produtos e processos - na produção existente e sistemas de consumo. Inovação 
incremental pode fazer uma importante contribuição em melhorar a eco eficiência dos processos de produção e desempenhos de bens em curto prazo, em algum grau.

Silveira, Backes e Kobayashi (2017) destacam, de forma mais abrangente, que estudos que revisam essa literatura de empreendedorismo sustentável, a exemplo de Hall, Daneke e Lenox (2010), Levinsohn (2013), Klewitz e Hansen (2014), Schaefer, Corner e Kearins (2015) e Schaltegger, Ludeke-Freund e Hansen (2016), têm apontado que o empreendedorismo tem sofrido influência das "questões entendidas como sustentáveis", e que o empreendedorismo sustentável, por natureza, tem sido considerado abrangente e transversal.

Quanto aos aspectos especificamente voltados às atitudes e comportamentos sociais, ao empreendedor sustentável e às ações voltadas para o empreendedorismo a revisão de literatura de Silveira, Backes, e Kobayashi (2017) destaca o artigo de Kuckertz e Wagner (2010). Este artigo se configura como uma pesquisa teórico-aplicada, onde os autores consideraram estudantes e ex-estudantes de cursos de ciências e engenharia como respondentes, no âmbito técnico da Universidade de Munique (TUM), uma das maiores e mais respeitadas universidades técnicas da Alemanha. Afirmando estar interessados em indivíduos preocupados com questões ambientais e sociais, e com a sustentabilidade, buscaram identificar os que poderiam potencialmente estar ainda interessados em apoiar iniciativas e formar empresas empreendedoras, com a ideia de sustentabilidade. Os autores mediram a intenção empreendedora dos estudantes e compararam com a orientação para a sustentabilidade. Em outras palavras, buscaram responder à questão de como a orientação para a sustentabilidade e as intenções empreendedoras estão relacionadas na prática. Considerando que a teoria do empreendedorismo e a teorização do desenvolvimento sustentável estão próximas, uniram debates sobre o empreendedorismo para o desenvolvimento sustentável com as principais teorias do empreendedorismo. Forneceram, assim, um equilíbrio e enriqueceram os modelos conceituais sobre empreendedorismo sustentável. Consideraram, Kuckertz e Wagner (2010), que o empreendedorismo sustentável está claramente associado à promessa de conceitos mais tradicionais de empreendedorismo, trazendo potencial adicional tanto para a sociedade como para o meio ambiente. Ao finalizar o estudo os dois autores propuseram medidas para alimentar o potencial para o empreendedorismo sustentável. E para o ensino de empreendedorismo sustentável. Esses autores seguem a linha de que o empreendedorismo sustentável surge em razão das falhas de mercado. (Kuckertz \& Wagner, 2010).

Nesse contexto de estudo a intenção de empreender, de forma social e sustentável, apresenta-se como base para uma decisão, claramente consciente e consequentemente 
planejada, que compele o indivíduo para um conjunto de atos e ações buscando iniciar um negócio (Thompson, 2009). Convém destacar, para ampliar o entendimento do assunto, que a intenção tem origem na Teoria do Comportamento Planejado (TCP) de Ajzen (1985, 1991). Essa TCP foi derivada, por sua vez, da Teoria da Ação Racional (TRA) de Fishbein e Ajzen (1975) e de Ajzen e Fishbein (1980), onde a ação racional se preocupa com a intenção comportamental. A Teoria do Modelo do Evento Empresarial (MME) de Shapero e Sokol (1982) e Shapero (1984) também alicerçaram a intenção de realizar determinado comportamento.

Schlaegel e Koenig (2014) compararam as duas teorias, a TCP e a MME, evidenciando os pontos convergentes, e confirmando que a TCP ampara a intenção de empreender, mais especificamente. Lortie e Castogiovanni (2015) também reconheceram que a TCP se destaca quanto à fundamentação da teoria da intenção voltada para o empreendedorismo, a intenção empreendedora. Liñán e Fayolle (2015), da mesma forma, evidenciaram que a TCP predomina como seminal quando se trata do tema de intenção empreendedora. No Brasil, mais recentemente, os trabalhos de Santos, Martins e Silveira (2016), e Silveira, Ferreira, Silvente e Cunha (2017) confirmaram que a TCP amparou a intenção empreendedora, com base em resultados de estudos de cunho bibliométrico e de revisão de literatura.

De forma resumida, pode-se afirmar que a TCP (Ajzen, 1991) preconizou que os comportamentos podem ser considerados intencionais e previstos pela intenção existente para o comportamento individual. A intencionalidade da ação pode ser fundamentada na psicologia cognitiva e se propõe a explicar e prever o comportamento humano. Nos estudos voltados para a intenção empreendedora, com base nos estudos do comportamento planejado, há evidências de que essas intenções se constituem em antecedentes de ações para empreender (Krueger, Reilly, \& Carsud, 2000). De forma geral, a pesquisa aplicada de intenção empreendedora considerou, ao longo do tempo, estudantes de ensino superior como população e amostra, e as universidades como organismos que desempenharam importante papel no processo de ensino de empreendedorismo. As universidades, dessa forma, tornaram-se campo de investigação sobre o tema, em razão do papel que passaram a ter na sociedade. Reconhecidamente constituíram-se em organizações que habilitam e tornam competentes os indivíduos; onde estes se tornam, por sua vez, protagonistas do próprio desempenho e promotores do desenvolvimento social, econômico, local e regional. Nesse sentido, estudos de intenção empreendedora têm considerado os estudantes universitários como sujeitos sociais capazes de apresentar intenção 
empreendedora, conforme evidenciam Fayolle e Gailly (2013). E de desenvolverem carreiras empreendedoras.

Considerando a pesquisa de Liñán, Urbano e Guerrero (2011) como um dos estudos mais expressivos nessa temática, realizada em contexto de universidades, ela foi adotada como fundamento teórico nessa pesquisa. A pesquisa de Liñán, Urbano e Guerrero (2011) toma como base a TCP, de Ajzen (2006, 2012), apresentando um instrumento de mensuração denominado Entrepreneurial Intention Questionnaire (EIQ). Esse instrumento foi utilizado como medida psicométrica, voltado a verificar o grau da intenção de empreender dos estudantes de ensino superior. Esse instrumento foi fruto da revisão e atualização do instrumento de coleta de dados verificado e testado anteriormente por Liñán (2008) e Liñán e Chen (2006, 2009). Os constructos considerados no EIQ foram: Atitude Pessoal, Normas Subjetivas, Controle do Comportamento Percebido e Intenção Empreendedora. Nesse sentido Souza, Silveira e Nascimento (2017) explicam que a teoria de Ajzen $(1991,2012)$ apresenta um conjunto de três constructos que antecedem a intenção de um comportamento: 1) atitude pessoal frente a esse comportamento; 2) norma subjetiva referente ao comportamento advindo do meio ambiente em que se insere o indivíduo; e 3) percepção sobre a forma de controle desse comportamento. Os três constructos derivam de crenças comportamentais, podendo facilitar ou impedir a concretização de determinada ação. E, por sua vez, induzem o indivíduo a uma atitude favorável ou desfavorável quanto a determinada ação. Essa teoria, a TCP de Ajzen (1991) pressupõe que é possível prever se um indivíduo vai apresentar determinado comportamento no futuro.

Essa teoria se voltou à Intenção Empreendedora Social e à Intenção Empreendedora, ambas em fase de desenvolvimento e construção, necessitando, ainda, de pesquisas científicas aplicadas que contribuam para sua consolidação.

\section{Método de pesquisa}

O delineamento metodológico para realização desta pesquisa foi descritivo.

Quanto aos procedimentos de coleta de dados a pesquisa foi de levantamento, com a adoção de instrumento de coleta de dados, em forma de questionário estruturado, em três blocos, da seguinte forma: 


\section{Orientação sustentável}

A primeira parte do segundo instrumento de coleta de dados enfocou a orientação sustentável tomando como base os aspectos de visão social e intenção empreendedora social. As questões foram construídas com base no que preconizam Kuckertz e Wagner (2010), de forma mais específica. Em alguns aspectos o estudo de Shepherd e Patzelt (2011), Navickiene, Fominiene e Dias (2015), Stal e Bonnedahl (2016) também amparam essa construção, bem como a revisão de literatura desenvolvida por Silveira, Backes, e Kobayashi (2017).

\section{Intenção empreendedora}

Esta parte foi estruturada com base no Entrepreneurial Intention Questionnaire (EIQ), revisado e proposto por Liñán, Urbano e Guerrero (2011). O questionário constituiu-se em uma escala psicométrica elaborada justamente para medir a Atitude Pessoal, as Normas Subjetivas, o Controle do Comportamento Percebido e a Intenção Empreendedora dos sujeitos sociais de pesquisa.

O EIQ revisado por Liñán, Urbano e Guerrero (2011) foi estruturado de A1 a A20 para mensurar as construções centrais da TCP (Ajzen, 1991, 2006, 2012) da seguinte forma:

a) Atitude Pessoal - A2 - revertida, A10, A12 - revertida, A15 e A18;

b) Normas Subjetivas - A3, A8, A11;

c) Controle do Comportamento Percebido - A1, A5 revertido, A7, A14, A16 revertida, A20;

d) Intenção Empreendedora - A4, A6, A9 - revertida, A13, A17 e A19 revertida.

\section{Características dos respondentes}

Características pessoais e socioeconômicas quanto aos aspectos de: gênero, idade, estado civil, renda própria e renda familiar foram estruturadas no sentido de conhecer a realidade dos respondentes para melhor caracterizá-los quanto ao objeto de estudo.

Convém ressaltar que tanto as partes estruturadas, com base principalmente em Kuckertz e Wagner (2010), quanto as construídas com a adoção do EIQ (Liñán, Urbano e Guerrero (2011), foram consideradas questões fechadas e escalas, em níveis de sete pontos, 
variando de "discordo totalmente" (1) "a concordo totalmente" (7), conforme escala do tipo Likert. As demais partes foram estruturadas com questões de assinalar e de preenchimento.

Convém ressaltar ainda que as questões da escala referentes ao instrumento de coleta de dados de orientação sustentável individual foram pretextadas. Para tanto, um grupo de 15 alunos de curso de graduação em administração de outra universidade, não situada em Chapecó, realizaram o teste para verificar sua inteligibilidade. Uma das questões foi modificada em razão do referido pré-teste.

A parte referente ao $E I Q$ não foi objeto de realização de um pré-teste pelo objetivo de se verificar a inteligibilidade das questões da escala psicométrica traduzidas para o português e adaptadas para a presente pesquisa. Essa escala já foi adotada, anteriormente, no Brasil, com estudantes universitários, nas pesquisas de Souza (2015) e Souza e Silveira (2016), Souza, Silveira e Nascimento (2017).

A coleta de dados primários foi realizada com alunos das últimas fases de graduação do Curso de Administração da Unoesc Chapecó, nos dias 17 e 21 de julho de 2017. Em virtude do período de férias e do reduzido número de questionários válidos, nova coleta foi realizada de 9 a 13 de outubro de 2017. A amostra intencional, de conveniência, não probabilística e por acessibilidade foi formada pelos alunos presentes no momento de coleta de dados. Responderam ao questionário os alunos que, espontaneamente, concordaram em participar da pesquisa e responder ao solicitado no instrumento de coleta de dados. Essa amostra de pesquisa, segundo Barbetta (2010) constitui-se, em parte, da população que representa os respondentes e que conserva as mesmas características da população. A amostra da coleta de dados totalizou 70 respondentes. O número de questionários válidos foi de 51, depois da consistência da base de dados. Esse número, apesar de ser menor que 100 unidades, foi considerado para a pesquisa realizada. A consequente digitação dos dados ocorreu em planilha Excel, no final de outubro de 2017.

A estatística descritiva foi adotada como procedimento de análise de dados, conforme sustentado por Wheelan (2016) e Bussab e Morettin (2017).

\section{Descrição e análise dos resultados}

A descrição e análise dos resultados seguiu a ordem dos objetivos específicos.

A análise descritiva foi realizada, primeiramente, em relação ao perfil dos alunos ou discentes respondentes. Tal resultado corresponde ao primeiro objetivo específico de pesquisa 
- as características de gênero, idade, estado civil, renda própria e renda familiar. O procedimento estatístico adotado foi o de contagem simples de frequência.

\section{Características dos alunos respondentes}

Na Tabela 1 apresenta-se o gênero dos discentes participantes da pesquisa.

Tabela 1 - Gênero - Discentes.

\begin{tabular}{|c|c|}
\hline Gênero & $\%$ \\
\hline Masculino & 52,95 \\
\hline Feminino & 47,05 \\
\hline Total & 100 \\
\hline
\end{tabular}

Tabela 2 - Idade - Discentes.

\begin{tabular}{|c|c|c|c|c|c|c|}
\hline Idade & Até 20 anos & $21-25$ anos & $\begin{array}{c}26-30 \\
\text { Anos }\end{array}$ & $\begin{array}{c}31-35 \\
\text { Anos }\end{array}$ & Acima de 36 anos & Total \\
\hline$\%$ & 5,90 & 72,53 & 15,67 & 5,90 & 0 & 100 \\
\hline
\end{tabular}

Tabela 3 - Estado Civil - Discentes.

\begin{tabular}{|l|c|}
\hline Estado Civil & $\%$ \\
\hline Solteiro & 78,43 \\
\hline Casado & 13,72 \\
\hline Viúvo & 0 \\
\hline Divorciado/Separado & 0 \\
\hline Outros & 7,85 \\
\hline Total & 100 \\
\hline
\end{tabular}

Tabela 4 - Renda mensal - Discentes.

\begin{tabular}{|c|c|c|c|c|c|c|}
\hline $\begin{array}{c}\text { Renda } \\
\text { Mensal }\end{array}$ & $\begin{array}{c}\text { Ainda não tenho } \\
\text { renda própria }\end{array}$ & $\begin{array}{c}\text { Até } \mathrm{R} \$ \\
880,00\end{array}$ & $\begin{array}{c}\mathrm{R} \$ 880,00 \text { a } \mathrm{R} \$ \\
4.399,00\end{array}$ & $\mathrm{R} \$ 4.400,00$ a $\mathrm{R} \$$ & $\begin{array}{c}\text { Acima de } \mathrm{R} \$ \\
8.799,00\end{array}$ & Total \\
\hline$\%$ & 7,85 & 7,85 & 68,62 & 15,68 & 0 & 100 \\
\hline
\end{tabular}

Tabela 5 - Renda familiar - Discentes.

\begin{tabular}{|c|c|c|c|c|c|}
\hline Renda & Até $\mathrm{R} \$$ & $\mathrm{R} \$ 880,00-\mathrm{R} \$$ & $\mathrm{R} \$ 4.400,00-\mathrm{R} \$$ & Acima de $\mathrm{R} \$$ & Total \\
Familiar & 880,00 & $4.399,00$ & $8.799,00$ & $8.800,00$ & \\
\hline$\%$ & 0 & 58,82 & 27,45 & 13,73 & 100 \\
\hline
\end{tabular}

Os resultados indicam que a maioria dos respondentes é do gênero masculino. A diferença entre os gêneros, entretanto, não ultrapassa o percentual de 5,90\%. Ou seja, o número referente aos gêneros masculino e feminino é muito próximo.

A idade predominante $(72,53 \%)$ dos alunos respondentes encontra-se entre 21 e 25 anos. Os alunos de 26 a 30 anos correspondem a 15,67\%. Os alunos que predominaram como respondentes são jovens, havendo, ainda, 5,89 elementos que não atingiram os 20 anos. 
Quanto ao estado civil dos respondentes, os solteiros são maioria $(78,43 \%)$. Com o predomínio dos alunos com pouca idade é natural que estejam solteiros. Os casados correspondem a 13,76\%. A renda mensal e a renda familiar dos alunos respondentes encontramse em $\mathrm{R} \$ 880,00$ e $\mathrm{R} \$ 4.399,00$, correspondendo a $68,62 \%$ e 58,82\%, respectivamente.

Estes resultados se assemelham ao encontrado por autores que investigaram alunos de cursos de graduação em seus estudos quanto à intenção de empreender. De forma geral, encontraram jovens estudantes, com gênero masculino predominando com percentuais próximos, idade entre 21 e 25 anos, estado civil solteiros, e renda mensal e familiar próxima de salários mínimos, guardando as devidas proporções em termos de tempo e de países. (Couto, Mariano \& Mayer, 2010; Hecke, 2011; Liñán, Urbano \& Guerrero, 2011; Naia, 2013; Souza, 2015; e Souza \& Silveira, 2016). O encontrado se assemelha aos trabalhos anteriores que guardam semelhança com o aqui realizado.

\section{Visão social}

Em seguida, a análise descritiva voltou-se para a Visão Social dos respondentes. Aqui oito enfoques corresponderam ao enunciado nas questões. Este item integrou o segundo objetivo de pesquisa, que identificou a visão social dos respondentes. Para tanto, o procedimento estatístico adotado foi o de Ranking Médio e o Desvio Padrão. Cabe destacar que, nessa parte, 48 alunos responderam completa e corretamente sobre a visão social.

O Ranking Médio (RM) refere-se ao ponto de equilíbrio de determinada frequência ou à concentração de dados de uma distribuição. O RM foi adotado para estabelecer o grau de concordância dos alunos respondentes da pesquisa quanto à visão social, à intenção empreendedora social e à intenção empreendedora. Ele possibilitou verificar a pontuação de concordância ou de discordância das questões do questionário, considerando a escala do tipo Likert de 7 pontos. Os valores menores que 4 foram considerados discordantes, e os maiores que 4, concordantes. O valor 4, em específico, foi considerado "indiferente" ou "sem opinião".

O desvio padrão (DP) corresponde a uma medida que indica a dispersão dos dados dentro de uma amostra em relação à média, objetiva evidenciar a regularidade de um conjunto de dados e indica o grau de oscilação destes em comparação com a média dos valores do conjunto. 
Optou-se por esses procedimentos estatísticos uma vez que, quando se calcula o desvio padrão juntamente com a média de diferentes grupos, obtêm-se mais informações para avaliar e diferenciar seus comportamentos.

Tabela 6 - Visão social - Discentes.

\begin{tabular}{|l|l|l|}
\hline Vida Social & Ranking médio & Desvio padrão \\
\hline A01 Sou capaz de identificar uma necessidade social. & 5,38 & 1,43 \\
\hline A02 Sou capaz de criar uma clara visão social. & 4,92 & 1,46 \\
\hline A03 Estou fortemente comprometido com uma visão social. & 4,73 & 1,48 \\
\hline A04 Tenho posição voltada para questões sociais . & 4,81 & 1,51 \\
\hline A05 Estou determinado a satisfazer uma necessidade social. & 4,88 & 1,55 \\
\hline A06 Estou determinado a ser um agente de mudança social . & 4,65 & 1,75 \\
\hline A07 Não sou propenso a seguir questões que não sejam sociais. & 4,08 & 1,74 \\
\hline A08 Tenho forte motivação para defender uma necessidade social. & 4,83 & 1,53 \\
\hline
\end{tabular}

A questão Sou capaz de identificar uma necessidade social obteve o maior RM, ou seja, a maior concordância, situando-se acima do ponto médio 4. Essa questão apresentou o menor DP, indicando maior homogeneidade na resposta dos alunos. As demais questões ficaram próximas do ponto 4, indicando, no mínimo, média tendência para reconhecimento e inclinação para valores sociais.

Para Kuckertz e Wagner (2010), “O nível de orientação média da sustentabilidade já é bastante alta em todas as nossas amostras (3.36 em uma escala de cinco pontos)", conforme evidenciado no trabalho realizado por esses dois autores. (Kuckertz \& Wagner, 2010, p. 534).

\section{Intenção empreendedora social}

Da mesma forma, para a análise descritiva da Intenção Empreendedora Social foi adotado o procedimento estatístico de RM e DP. O objetivo buscou apontar a intenção empreendedora social.

Tabela 7 - Intenção Empreendedora Social - Discentes.

\begin{tabular}{|l|c|c|}
\hline \multicolumn{1}{|c|}{ Intenção Empreendedora Social } & $\begin{array}{l}\text { Ranking } \\
\text { Médio }\end{array}$ & $\begin{array}{l}\text { Desvio } \\
\text { Padrão }\end{array}$ \\
\hline $\begin{array}{l}\text { B01 Se eu pudesse escolher livremente preferiria ser um empreendedor social } \\
\text { a um funcionário de empresa pública ou privada. }\end{array}$ & 4,96 & 1,58 \\
\hline B02 Meu objetivo é tornar-me um empreendedor social no futuro. & 4,79 & 1,64 \\
\hline B03 Vou ganhar a vida como empreendedor social. & 4,33 & 1,67 \\
\hline $\begin{array}{l}\text { B04 Para mim, o empreendedorismo social é uma provável escolha de carreira } \\
\text { profissional. }\end{array}$ & 4,44 & 1,68 \\
\hline
\end{tabular}

R.G. Secr., GESEC, São Paulo, v. 9, n. 2, p 179-204, mai./ago. 2018. 
O RM situou-se um maior do que 4. A questão que enunciou que Se eu pudesse escolher livremente preferiria ser um empreendedor social a um funcionário de empresa pública ou privada apresentou o maior RM e o DP com o menor valor. Essa resposta pareceu indicar que, em uma situação de livre escolha, o aluno tem intenção de se tornar um empreendedor social. Tendência para escolha de carreira como empreendedor social. A resposta indicou maior grau de homogeneidade e de convergência nas respostas dos alunos respondentes, ou seja, concentração na resposta. Os alunos são coesos em apontar e reconhecer esta intenção empreendedora social. Nessa parte do questionário foram 48 respondentes.

Com base no estudo de Kuckertz e Wagner (2010) pode-se entender que tais resultados evidenciam que esta população jovem, formada por estudantes menos experientes, guardam preocupação com questões éticas, sociais e ambientais, ou seja, valores sociais. E que é provável que se traduza em intenção empreendedora e posterior comportamento empreendedor potencial sustentável. Porém, dado que a maioria das atividades empresariais ocorre alguns anos depois de o indivíduo completar um programa de ensino de graduação "há uma lacuna entre o que os estudantes como potenciais empreendedores futuros acreditam que poderiam fazer, e o que eles vão fazer na verdade, em sua carreira”. (Kuckertz \& Wagner, 2010, p. 534).

\section{Intenção empreendedora}

Continuando a análise descritiva da Intenção Empreendedora, foi adotado, igualmente, o procedimento estatístico de ranking médio e desvio padrão. Aqui o objetivo foi o de distinguir a intenção empreendedora. Nesse bloco de questões foram respondidas por 48 alunos. 
Silveira, A., Nascimento, S., Riboldi, L (2018)

Tabela 8 - Intenção Empreendedora - Discentes.

\begin{tabular}{|c|c|c|}
\hline Intenção Empreendedora & $\begin{array}{l}\text { Ranking } \\
\text { Médio }\end{array}$ & $\begin{array}{l}\text { Desvio } \\
\text { Padrão }\end{array}$ \\
\hline C01 Começar e manter um negócio próprio seria fácil para mim. & 4,08 & 1,68 \\
\hline C02 Uma carreira como empreendedor não é atraente para mim. & 3,50 & 1,75 \\
\hline C03 Meus amigos aprovariam minha decisão de começar um negócio. & 4,71 & 1,46 \\
\hline C04 Estou preparado pra fazer qualquer coisa para ser um empreendedor. & 4,06 & 1,78 \\
\hline $\begin{array}{l}\text { C05 Acredito que seria completamente incapaz de começar um negócio } \\
\text { próprio. }\end{array}$ & 3,48 & 1,77 \\
\hline C06 Farei todo o esforço necessário para iniciar e manter meu próprio negócio. & 4,96 & 1,65 \\
\hline C07 Sou capaz de controlar o processo de criação de um novo negócio. & 4,90 & 1,15 \\
\hline $\begin{array}{l}\text { C08 Meus parentes mais próximos aprovariam minha decisão de começar um } \\
\text { novo negócio. }\end{array}$ & 5,19 & 1,38 \\
\hline C09 Tenho sérias dúvidas em algum dia começar um negócio próprio. & 4,17 & 1,64 \\
\hline $\begin{array}{l}\text { C10 Se eu tivesse oportunidade e recursos, eu adoraria começar um novo } \\
\text { negócio próprio. }\end{array}$ & 5,40 & 1,32 \\
\hline $\begin{array}{l}\text { C11 Meus colegas de trabalho aprovariam minha decisão de abrir um novo } \\
\text { negócio. }\end{array}$ & 5,08 & 1,58 \\
\hline $\begin{array}{l}\text { C12 Diante de várias opções preferiria qualquer coisa, exceto começar um } \\
\text { negócio próprio. }\end{array}$ & 3,40 & 1,98 \\
\hline C13 Estou determinado a criar um negócio inovador no futuro. & 4,81 & 1,54 \\
\hline $\begin{array}{l}\text { C14 Se eu tentasse começar um negócio, teria uma grande chance de ser bem- } \\
\text { sucedido. }\end{array}$ & 5,04 & 1,34 \\
\hline C15 Ser um empreendedor me traria grande satisfação. & 5,17 & 1,31 \\
\hline C16 Seria muito difícil para eu desenvolver uma ideia de um novo negócio. & 4,02 & 1,73 \\
\hline C17 Meu objetivo profissional é ser um empreendedor. & 4,56 & 1,56 \\
\hline C18 Ser um empreendedor implica mais vantagens que desvantagens pra mim. & 4,71 & 1,58 \\
\hline C19 Tenho muito pouca vontade de começar um negócio algum dia. & 3,29 & 1,75 \\
\hline C20 Conheço todos os detalhes práticos para começar um negócio. & 3,79 & 1,61 \\
\hline
\end{tabular}

Os resultados se apresentam, nesse bloco, segundo a TCP preconizada por Ajzen (1991), entendendo aqui o principio de que quanto mais favorável for a atitude pessoal, a norma subjetiva, e o controle do comportamento percebido, mais forte deverá ser a intenção do indivíduo em realizar um determinado comportamento (Ajzen, 1991). A intenção apresenta-se como um antecedente imediato do comportamento. Na presente pesquisa, especificamente do comportamento empreendedor.

No presente estudo, a Atitude Pessoal compreende as assertivas C02 revertida, C 10, $\mathrm{C} 12$ revertida, C15, e C18 do questionário de pesquisa. De forma clara, os alunos assinalaram: Se eu tivesse oportunidade e recursos, eu adoraria começar um novo negócio próprio e Ser um empreendedor me traria grande satisfação. O RM das duas assertivas mostrou-se maior que a média 4, sendo de 5,40 e 5,17. Afirmaram ainda que Ser um empreendedor implica mais vantagens que desvantagens pra mim, com RM de 4,41.

R.G. Secr., GESEC, São Paulo, v. 9, n. 2, p 179-204, mai./ago. 2018. 
As Normas Subjetivas, por sua vez, deixam evidente que Meus parentes mais próximos aprovariam minha decisão de começar um novo negócio, Meus colegas de trabalho aprovariam minha decisão de abrir um novo negócio e Meus amigos aprovariam minha decisão de começar um negócio. Os resultados do DM situaram-se em 5,19, 5,08 e 4,71, respectivamente, e confirmam essas aprovações. Indicaram ser importantes para os alunos, dentro do contexto que se refere ao meio ambiente em que eles vivem, ter a aprovação de parentes, colegas e amigos para empreender, conforme o que se apresenta na TCP (Ajzen, 1991, 2012).

No Controle do Comportamento Percebido, representado pelas assertivas C1, C5 revertido, C7, C 14, C16 revertido, C20, destacam-se as seguintes assertivas: Se eu tentasse começar um negócio, teria uma grande chance de ser bem-sucedido e Sou capaz de controlar o processo de criação de um novo negócio, representados por DM de 5,04 e 4,90, respectivamente. Da mesma forma, Começar e manter um negócio próprio seria fácil para mim, com RM de 4,08, se destaca.

As assertivas quanto à Intenção Empreendedora, C04, C06, C09 revertida, C13, C17 e C19 revertida, apresentam RM de 4,06 a 4,96. Esses resultados indicam, em ordem decrescente, que os alunos apresentam as seguintes intenções empreendedoras, prioritariamente: Farei todo o esforço necessário para iniciar e manter meu próprio negócio. Estou determinado a criar um negócio inovador no futuro e Meu objetivo profissional é ser um empreendedor. Esse resultado apresentou o DP menor, e mais homogêneo, indicando que os alunos apresentam grau de concordância e coesão com essas questões.

Os resultados sobre a intenção empreendedora de alunos de cursos de graduação em Administração assemelham-se ao encontrado Liñán, Nabi e Krueger (2013), quando voltaram a testar o QIE, com alunos ingleses e espanhóis. Também com os estudos de Naia (2013), Souza (2015), Souza e Silveira (2016), Sutha e Sankar (2016) e Souza e Silveira (2018), entre outros.

Entretanto, convém entender que, na verdade, os alunos respondentes ainda estão estudando para fundamentar habilidades, competências e intenção empreendedora. No estudo de Kuckertz e Wagner (2010, p. 534) transparece a preocupação e o questionamento para esse ponto específico. Os autores questionam o que segue, com base nos resultados de seu artigo: "Quais medidas podemos tomar para não desperdiçar o potencial óbvio entre os nossos alunos?" Entre várias sugestões destaca-se a que deixa claro que se concentrar no nível de graduação permite aos educadores a inclusão precoce de questões de sustentabilidade. Elas potencializam e equilibram o efeito da exposição dos negócios aos estudantes. Nesse nível de educação 
superior o efeito da experiência comercial inicial pode ser fortemente moderado pela intervenção educacional de habilidade e competência, de forma a apoiar os indivíduos a continuarem a ser empreendedores em sua orientação para a sustentabilidade. Deixando claro que o empreendedorismo sustentável está claramente associado à promessa de conceitos mais tradicionais de empreendedorismo, os dois autores, Kuckertz e Wagner (2010) advogam que a plataforma em sala de aula para empreendedores empenhados em buscar modelos de negócios sustentáveis aumentará o nível de intenção empresarial entre seus públicos, e que o potencial das imperfeições do mercado, que revelam oportunidades para empreender, devem ser um componente padrão de todo currículo de empreendedorismo. Deixam claro, ainda, a importância da pós-graduação para o desenvolvimento do empreendedorismo sustentável. (Kuckertz \& Wagner, 2010, p. 535)

Também o recente estudo de Ploum (2018) alerta para este ponto: o empreendedorismo é cada vez mais identificado como um catalisador de soluções para problemas de sustentabilidade. O processo empreendedor como tal parece ser implica que empreendedores sustentáveis tenham habilidades, conhecimentos e valores diferentes, e que permitam alcançar metas de sustentabilidade por meio de suas ações empreendedoras. $\mathrm{O}$ contexto do agente de mudanças específicas são geralmente combinações de competências-chave para o desenvolvimento sustentável. A continuidade de conhecimentos é importante nesse contexto.

\section{Conclusão}

Os principais teóricos que trataram do assunto foram Dean e McMullen (2007), Kuckertz e Wagner (2010), Hall, Daneke e Lenox (2010), De Clercq e Voronov (2011), Levinsohn (2012), Klewitz e Hansen (2014), Navickiene, Fominiene e Dias (2015), Schaefer, Corner e Kearins (2015) e Schaltegger, Ludeke-Freund e Hansen (2016). Mostram-se adequados para amparar o assunto de empreendedorismo sustentável.

O método adotado foi adequado, e o instrumento de coleta de dados mostrou-se pertinente para o estudo proposto, pois permitiu evidenciar a visão social, a intenção empreendedora social e a intenção empreendedora dos alunos do Curso de Administração da Unoesc Chapecó, em 2017.

Os resultados mostram que os alunos participantes da pesquisa pertencentes do Curso de Administração da Unoesc Chapecó podem ser caracterizados por serem predominantemente do gênero masculino $(52,95 \%)$, com idades de 21 a $25 \operatorname{anos}(72,53 \%)$, solteiros $(78,43)$, com 
renda própria e renda familiar de $\mathrm{R} \$ 880,00$ a $\mathrm{R} \$ 4.399,00 \quad(68,62 \%$ e 58,82\%, respectivamente).

A identificação quanto à concordância em relação à visão social dos alunos pesquisados mostrou que o RM oscilou entre 5,38 e 4,65. Essa concordância, em uma escala de 7 pontos, situou-se em "indiferente" e "concordo um pouco".

A verificação da intenção empreendedora social indicou que os alunos apresentaram um entendimento mediano sobre o assunto. Em termos de intenção empreendedora social, o RM ficou entre 4,96 e 4,33, com concordância próxima de indiferente.

A mensuração da intenção empreendedora dos alunos respondentes, com base no $E I Q$, teve concordância de 5,40 a 4,06 nas questões afirmativas.

Quanto ao DP, os resultados elevados encontraram-se bem distribuídos em torno da média. O DP pequeno indicou os que estavam condensados próximos da média. Resumindo, pode-se afirmar: amostra com DP menor é homogênea, amostra com DP maior é heterogênea.

Nos três aspectos pesquisados, os alunos apresentaram um nível intermediário nas questões respondidas. Em relação às pesquisas aplicadas desenvolvidas em empreendedorismo sustentável, algumas, como as de Lengler e Silva (2008), Kuckertz e Wagner (2010), Pimentel, Oliveira e Reinaldo (2012), Barboza, Leiman e Wei-Skillern (2015) possibilitam verificar que as respostas ficaram, também, em nível mediano. Há entendimento de que o nível de orientação média da sustentabilidade, em escala de cinco pontos, pode ser considerada alta para esse tipo de amostra (Kuckertz \& Wagner, 2010, p. 534).

A questão de pesquisa foi respondida. Os alunos apresentam visão social, intenção empreendedora social e intenção empreendedora. Há indicação de homogeneidade da amostra.

Das limitações da pesquisa realizada cita-se o número dos respondentes, que ficou menor que 100 unidades, número recomendado para estudos qualitativos. Pode-se observar que em Pimentel, Oliveira e Reinaldo (2012), o número reduzido da amostra foi considerada uma limitação de pesquisa junto aos 33 dirigentes de micro e pequenas empresas. O número dos respondentes de Barboza, Leiman e Wei-Skillern (2015) foi de 58 gestores de micro e pequenas empresas. Também abaixo de 100 unidades. Apesar da limitação da pesquisa, ela contribuiu para o aumento do conhecimento sobre o assunto.

Implícito fica aqui o entendimento da importância da educação empreendedora voltada para o empreendedorismo sustentável. Esse ponto merece ser retomado.

Da mesma forma, ao finalizar este estudo sugere-se que outras pesquisas precisam ser desenvolvidas em outros contextos, com outros sujeitos sociais respondentes para que se 
continue ampliando o estudo do assunto. Da mesma maneira, outras metodologias deverão ser adotadas para a realização de futuras pesquisas em empreendedorismo sustentável.

\section{Referências}

Ajzen, I. (2006). Constructing a TPB Questionnaire: conceptual and methodological considerations. Recuperado de: http://www.unix.oit.umass.edu/tpb.measurement.pdf . (1985). From intentions to actions: A theory of planned behavior. In Kuhl, J. \& Beckman, J. (Eds.), Action-control: from cognition to behavior (pp. 11-39). Heidelberg: Springer.

. (1991). The theory of planned behavior. Organizational Behavior and Human Decision Processes, 50(2), 179-211.

. (2012). The theory of planned behavior. In Lange, A. P. A. M.; Kruglanski W.; \& Higgins, E. T. (Eds.). Handbook of theories of social psychology (pp. 438-459). London: Sage.

Ajzen, I. \& Fishbein, M. (1980). Understanding attitudes and predicting social behavior. Englewood Cliffs, NJ: Prentice-Hall.

Almeida, G. O. (2013). Valores, atitudes e intenção empreendedora: um estudo com universitários brasileiros e cabo-verdianos. Tese de doutorado, Fundação Getúlio Vargas, São Paulo.

Barbetta, P. A. (2010). Estatística aplicada às ciências sociais (7a ed.). Florianópolis: Ed. da UFSC.

Barboza, J. V. S.; Leiman, E. L.; \& Wei-Skillern, J. (2015). Sustentabilidade na visão de gestores de micro e pequenas empresas na região do Paraná. Revista da Micro e Pequena Empresa, 9(2), 17-29. 
Borges, C.; Borges, M. M.; Ferreira, V. R. S.; Najberg, E.; \& Tete, M. F. (2013). Empreendedorismo sustentável: proposição de uma tipologia e sugestões de pesquisa. Revista de Empreendedorismo e Gestão de Pequenas Empresas, 2(1), 77-100.

Boszczowski, A. K. \& Teixeira, R. M. (2012). O empreendedorismo sustentável e o processo empreendedor: em busca de oportunidades de novos negócios como solução para problemas sociais e ambientais. Revista Economia \& Gestão, 12(29), 109-127.

Brunelli, M. \& Cohen, M. (2012). Definições, diferenças e semelhanças entre empreendedorismo sustentável e ambiental: análise do estado da arte da literatura entre 1990 e 2012. Anais do Encontro Nacional da Associação Nacional de Pós-graduação e Pesquisa em Administração. Rio de Janeiro, 36.

Bussab, W. O. \& Morettin, P. A. (2017). Estatística básica (9a ed.). São Paulo: Saraiva.

Cohen, B. \& Winn, M.I. (2007). Market imperfections, opportunity and sustainable entrepreneurship. Journal of Business Venturing, 22, 29-49.

Couto, C. L. P.; Mariano, S. R. H.; \& Mayer, V. F. (2010). Medição da intenção empreendedora no contexto brasileiro: desafios da aplicação de um modelo internacional. Anais do Encontro Nacional dos Programas de Pós-graduação em Administração. Rio de Janeiro, 34.

Dean, T. J. \& McMullen, J. S. (2007). Toward a theory of sustainable entrepreneurship: reducing environmental degradation through entrepreneurial action. Journal of Business Venturing, 22, 50-76.

De Clercq, D. \& Voronov, M. (2011). Sustainability in entrepreneurship: A tale of two logics. International Small Business Journal, 29(4), 322-344.

Fayolle, A. \& Gailly, B. (2013). The impact of entrepreneurship education on entrepreneurial attitudes and intention: hysteresis and persistence. Journal of Small Business Management. 
Fishbein, M. \& Ajzen, I. (1975). Belief, attitude, intention and behavior: an introduction to Theory and Research. Reading, MA: Addison-Wesley.

Hall, J. K.; Daneke, G. A.; \& Lenox, M. J. (2010). Sustainable development and entrepreneurship: past contributions and future directions. Journal of Business Venturing, 25, 439-448.

Hecke, A. P. (2011). A intenção empreendedora dos alunos concluintes dos cursos de graduação em administração e ciências contábeis das instituições de ensino superior de Curitiba-PR. Dissertação de mestrado, Universidade Federal do Paraná, Curitiba.

Hockerts, K. \& Wüstenhagen, R. (2010). Greening Goliaths versus emerging Davids: theorizing about the role of incumbents and new entrants in sustainable entrepreneurship. Journal of Business Venturing, 25, 481-492.

Kuckertz, A. \& Wagner, M. (2010). The influence of sustainability orientation on entrepreneurial intentions: investigating the role of business experience. Journal of Business Venturing, 25, 524-539.

Jolink, A. \& Niesten, E. (2015). Sustainable development and business models of entrepreneurs in the organic food industry. Business Strategic Environment, 24, 386401.

Klewitz, J. \& Hansen, E. G. (2014). Sustainability-oriented innovation of SMEs: a systematic review. Journal of Cleaner Production, 65, 57-75.

Krueger, N. F.; Reilly, M. D.; \& Carsrud, A. L. (2000). Competing models of entrepreneurial intentions. Journal of Business Venturing, 15(5-6), 411-432.

Lengler, L. \& Silva, T. N. (2008). Sustentabilidade, empreendedorismo e cooperação em associações de apicultores da região central do Rio Grande do Sul. Revista de Micro e Pequena Empresa, 2(2), 40-57. 
Levinsohn, D. (2013). Disembedded and beheaded? - a critical review of the emerging field of sustainability entrepreneurship. International Journal Entrepreneurship Small Business, 19(2), 190-211.

Liñán, F. (2008). Skill and value perceptions: How do they affect entrepreneurial intentions?. International Entrepreneurship and Management Journal, 4(3), 257-272.

Liñán, F. \& Chen, Y. W. (2006). Testing the Entrepreneurial Intention Model on a TwoCountry Sample. Research Paper. Universitat Autonoma de Barcelona, Spain.

. (2009, May). Development and cross-cultural application of a specific instrument to measure entrepreneurial intentions. Entrepreneurship Theory and Practice, 33(3), 593617.

Liñán, F. \& Fayolle, A. (2015). A systematic literature review on entrepreneurial intentions: citation, thematic analysis, and research agenda. International Entrepreneurship Management Journal.

Liñán, F.; Nabi, G.; \& Krueger, N. (2013). British and Spanish entrepreneurial intentions: a comparative study. Revista de Economía Mundial, 33, 73-103.

Liñán, F.; Urbano, D.; \& Guerrero, M. (2011, April). Regional variations in entrepreneurial cognitions: start-up intentions of university students in Spain. Entrepreneurship \& Regional Development, 23(3-4), 187-215.

Lortie, J. \& Castogiovanni, G. (2015, March). The theory of planned behavior in entrepreneurship research: what we know and future directions. International Entrepreneurship and Management Journal.

Lovison, M. (2014). Capital social e intenção empreendedora dos estudantes de administração de uma instituição de ensino superior da serra gaúcha. Dissertação de Mestrado, Universidade de Caxias do Sul, Caxias do Sul. 
Naia, A. M. P. (2013). Entrepreneurship education in sport sciences: implications for curriculum development. Tese de doutorado, Universidade de Lisboa, Lisboa, Portugal.

Nassif, V.; Prando, R.A.; \& Cosetino, H. M. (2010). Ações estatais assistencialistas e empreendedorismo social sustentável no Brasil: um estudo exploratório. Anais do Encontro de Estudos sobre Empreendedorismo e Gestão de Pequenas Empresas. Recife, 6.

Navickiene, R.; Fominiene, V. B.; \& Dias, F. (2015). Entrepreneurship in the sustainable Tourism sector. The case of tour operators in Lithuania. Transformations in Business \& Economics, 14(3), 138-153.

Pacheco, D. F.; Dean, T. J.; \& Payne, D. S. (2010). Escaping the green prison: entrepreneurship and the creation of opportunities for sustainable development. Journal of Business Venturing, 25, 464-480.

Pimentel, T. A. B.; Oliveira, L. G. L.; \& Reinaldo, H. O. A. (2012, outubro-dezembro). Análise das dimensões de empreendedorismo sustentável em micro, pequena e médias indústrias no Ceará. Reuna, 17(4), 85-104.

Pinkse, J. \& Groot, K. (2015). Sustainable entrepreneurship and corporate political activity: overcoming market barriers in the clean energy sector. Entrepreneurship Theory and Practice, 39(3), 633-654.

Ploum, L. (2018). The return of the Jedi in entrepreneurship? Developing a valeted competence framework for sustainable entrepreneurship and exploring the specific role of moral competences in the sustainable entrepreneurial process. ( $\mathrm{PhD}$ Thesis). Wageningen University \& Research, Wageningen, NL.

Rueda, S.; Moriano, J. A.; \& Liñán, F. (2015). Validating a theory of planned behavior questionnaire to measure entrepreneurial intentions. In Fayolle, A.; Kyrö, P. \& Liñán, (F. Eds.), Developing, Shaping and Growing Entrepreneurship (pp. 60-78). Cheltenham: Edward Elgar. 
Santos, E. B. A.; Martins, F. S.; \& Silveira, A. (2016). Intenção empreendedora: categorização, classificação de constructos e predição de modelo. Anais do Encontro Nacional dos Programas de Pós-graduação em Administração. Costa do Sauipe, 40.

Schaefer, K.; Corner, P. D.; \& Kearins, K. (2015). Social, environmental and sustainable entrepreneurship research: what is needed for sustainability-as-flourishing? Organization \& Environment, 28(4), 394-413.

Schaltegger, S.; Ludeke-Freund, F., \& Hansen, E. G. (2016). Business models for sustainability: a co-evolutionary analysis of sustainable entrepreneurship, innovation, and transformation. Organization \& Environment, 29(3), 264-289.

Schaltegger, S. \& Wagner, M. (2010) Sustainable entrepreneurship and sustainability innovation: Categories and interactions. Business Strategy and the Environment, 20(4), 222-237

Schlaegel, C. \& Koenig, M. (2014). Determinants of entrepreneurial intent: a meta-analytic test and integration of competing models. Entrepreneurship Theory and Practice, 38(2), 291-332.

Shapero, A. (1984). The entrepreneurial event. In Kent, C. A. (Ed.). The Environment for Entrepreneurship (pp. 21-40). Lexington: D.C. Heath \& Company.

Shapero, A. \& Sokol, L. (1982). The social dimensions of entrepreneurship. In Kent C. A., Sexton D. L.; \& Vesper, K. H. (Eds.), Encyclopedia of Entrepreneurship (pp. 72-90). Englewood Cliffs: Prentice-Hall.

Shepherd, D. A. \& Patzelt, H. (2011). The new field of sustainable entrepreneurship: studying entrepreneurial action linking "what is to be sustained" with "what is to be developed”. Entrepreneurship Theory and Practice, 35(1), 135-163. 
Sehnem, S.; Lucas, M.; \& Marques, P. (2015). Elaboração e aplicação dos indicadores de sustentabilidade em pequenas e médias empresas. Navus Revista de Gestão e Tecnologia, 5, 22-41.

Silveira, A., Backes, D. A. P.; \& Kobayashi, A. R. K. (July 2017). Sustainable entrepreneurship: the scientific production of the 21st century. Revista de Negócios, 22 (3), 22-37.

Silveira, A., Ferreira, C. C., Silvente, G. A.; \& Cunha, J. A. C. (2017, maio-agosto). Factors and approaches of entrepreneurial intention. Regepe - Revista de Empreendedorismo e Gestão de Pequenas Empresas, 6(2), 263-290.

Souza, R. S. (2015). Intenção empreendedora: validação de modelo em universidades federais de Mato Grosso do Sul, Brasil. Tese de doutorado, Universidade Nove de Julho, São Paulo.

Souza, R. S. \& Silveira, A. (2016). Intenção empreendedora: Validação do Entrepreneurial Intention Questionnaire (EIQ) em contexto brasileiro. Anais do Encontro Nacional dos Programas de Pós-Graduação em Administração. Costa do Sauipe, 40.

Souza, R.S. \& Silveira, A. (2018). Intención empreendedora en contexto universitário brasileño. Revista GUAL, 11 (2), 297-318.

Souza, R. S.; Silveira, A.; \& Nascimento, S. (2017). Ampliando a mensuração de intenção empreendedora: Estudo com discentes de graduação em universidades federais brasileiras. Anais do Encontro Nacional dos Programas de Pós-graduação em Administração. São Paulo, 41.

Stal, H. I. \& Bonnedahl, K. (2016). Conceptualizing strong sustainable entrepreneurship. Small Enterprise Research, 23(1), 73-84. 
Sutha, A. I., \& Sankar, P. (2016). Entrepreneurial Intention and Social Entrepreneurship among University Students in Chennai City. International Journal of Engineering Studies, 1, 93-106.

Thompson, E. R. (2009). Individual entrepreneurial intent: construct clarification and development of an internationally reliable metric. Entrepreneurship Theory and Practice, 33(3), 669-694.

Wagner, M. (2012). Entrepreneurship, innovation and sustainability: an introduction and overview. In Wagner, M. (Org.), Entrepreneurship, Innovation and Sustainability (pp. 1-9). Greenleaf.

Wheelan, C. (2016). Estatística: o que é, para que serve, como funciona. Rio de Janeiro: Zahar.

\section{Agradecimento:}

Programa de Bolsas de Estudo de Educação Superior UNIEDU/Pós-graduação UNOESC. 